\title{
FORMAÇÃO MÍNIMA PARA PROFESSOR DO ENSINO FUNDAMENTAL: OS EDITAIS DE CONCURSOS PÚBLICOS DA REGIÃO DE MARINGÁ/PR
}

\author{
Cléber dos Santos Gonçalves, Maria Luisa Furlan Costa. \\ Universidade Estadual de Maringá - UEL, Programa de Pós-Graduação em Educação, Maringá, PR. E-mail: \\ binho.clebergoncalves@gmail.com
}

\begin{abstract}
RESUMO
O presente artigo propõe uma análise das exigências de habilitação mínima nos concursos para professor do ensino fundamental na região de Maringá, no norte do estado do Paraná. O objetivo principal é identificar se o nível de cobrança está diretamente relacionado ao desempenho das instituições de ensino. Para tanto, além do confrontamento dos dados dos editais, explora a avaliação que cada município recebeu no último levantamento do Ideb (índice de Desenvolvimento da Educação Básica), em relação ao primeiro ciclo do ensino fundamental. Os resultados apontaram que a qualidade do ensino não está estreitamente condicionada à exigência de nível superior ou formção em nível médio, mas a outros fatores, sendo possivelmente um deles a capacitação continuada em serviço.
\end{abstract}

Palavras-chave: Formação; Ensino Fundamental; Concursos Públicos.

\section{MINIMUM TRAINING FOR TEACHERS OF FUNDAMENTAL EDUCATION: THE PUBLIC COMPETITION EDITORS OF THE REGION OF MARINGÁ / PR}

\begin{abstract}
The present article proposes an analysis of the requirements of minimum qualification in the competitions for teacher of the basic education of the region of Maringá, in the north of the state of Paraná. The main objective is to identify if the level of collection is directly related to the performance of the teaching institutions. To do so, in addition to comparing the data of the calls for proposals, it explores the evaluation that each municipality received in the last survey of Ideb (Index of Development of Basic Education) in relation to the first cycle of elementary education. The results pointed out that the quality of teaching is not strictly conditioned to the requirement of higher education or training at the intermediate level, but to other factors, possibly being one of them continuing training in service.
\end{abstract}

Keywords: Formation; Elementary School; Public Contests. 


\section{INTRODUÇÃO}

A formação inicial de professores para atuação na educação básica tem sido alvo e, ao mesmo tempo, motivação de estudos, recomendações e políticas públicas, por parte de órgãos e agências nacionais e internacionais. $O$ aspecto é tido como um dos principais a serem considerados, com vistas ao objetivo da melhoria da qualidade do ensino.

Seguindo tais orientações, a legislação brasileira, principalmente a partir da décadade 1990, passa a fomentar a discussão e o estabelecimento de políticas voltadas à formação dos professores. Não por acaso, dois documentos próprios do país ainda em vigência podem ser citados no tocante à preocupação com a qualificação docente: A LDBEN (Lei de Diretrizes e Bases da Educação Nacional), de 1996, e suas alterações e o Plano Nacional de Educação 2014/2024. Em ambos, é possível verificar a indicação da necessidade de impulsionar a formação daqueles que vão se dedicar ao magistério, como condição importante para a melhoria da qualidade educacional como um todo.

$\mathrm{Na}$ efetivação das diretrizes apontadas pelos documentos legais, é possível, contudo, encontrar condições que destoam do ideal exposto. No que se refere à habilitação mínima cobrada pelos municípios brasileiros para a admissão de professores para a docência na educação infantil e nos primeiros cinco anos do ensino fundamental, por exemplo, existe muita diferença em relação às exigências contidas nos editais de concursos públicos. Por conta de uma abertura legal, alguns municípios exigem formação em nível superior aos docentes, enquanto outros exigem apenas a formação em nível médio.

Por essa razão, para melhor compreender o que está sendo proposto e cobrado na atualidade, analisar editais de concursos públicos para a docência, confrontando os requisitos neles contidos com as orientações legais, passa a ser imperativo. Além disso, considera-senecessário, também, relacionar os últimos resultados obtidos no Ideb (Índice de Desenvolvimento da Educação Básica) pelos municípios que exigem formação em nível superior e os que admitem a formação em nível médio, de modo a verificar indícios que diferenciam tais localidades em resultados.

\section{METODOLOGIA}

A metodologia adotada nesta pesquisa, para o alcance dos objetivos, teve início com uma pesquisa bibliográfica e documental sobre a formação de professors no Brasil, como já se há discorrido e conforme as referências deste trabalho apontam. A partir de então, foi realizada uma análise a respeito de dois aspectos envolvendo os municípios da região de maringá: a exigência minima de formação para docente do ensino fundamental presente no ultimo concurso publico de provas e títulos; e a avaliação no Ideb (Índice de Desenvolvimento da Educação Básica) do primeiro ciclo do ensino fundamental, procurando identificar se as exigências de habilitação estão diretamente ligadas ao desempenho das instituições de ensino.

\section{RESULTADOS}

Desde a aprovação da LDBEN, de 1996, a preocupação com a habilitação inicial de docentes para a educação básica tornou-se mais intensa. É no Artigo 62 que o referido documento legal aponta as exigências mínimas para atuar na educação escolar organizada e sistematizada no Brasil. O texto inicial do artigo destacado apontava que:

A formação de docentes para atuar na educação básica far-se-á em nível superior, em curso de licenciatura, de graduação plena, em universidades e institutos superiores de educação, admitida, como formação mínima para o exercício do magistério na educação infantil e nas quatro primeiras séries do ensino fundamental, a oferecida em nível médio, na modalidade Normal. 
Com a Lei no 12.796, de 2013, que ampliou a duração do ensino fundamental, o Artigo 62 sofreu sua primeira modificação, passando a figurar com a seguinte redação:

A formação de docentes para atuar na educação básica far-se-á em nível superior, em curso de licenciatura, de graduação plena, em universidades e institutos superiores de educação, admitida, como formação mínima para o exercício do magistério na educação infantil e nos 5 (cinco) primeiros anos do ensino fundamental, a oferecida em nível médio na modalidade normal.

A terceira alteração no referido artigo ocorreu com a Lei 13.415, de 2017, cujo texto vigora na atualidade da seguinte forma:

A formação de docentes para atuar na educação básica far-se-á em nível superior, em curso de licenciatura plena, admitida, como formação mínima para o exercício do magistério na educação infantil e nos cinco primeiros anos do ensino fundamental, a oferecida em nível médio, na modalidade normal.

O Plano Nacional de Educação 2014/2024 destaca a importância e a necessidade de se ter professores com formação específica em nível superior. Na meta 15, está apontado como essencial "[...] que todos os professores e as professoras da educação básica possuam formação específica de nível superior, obtida em curso de licenciatura na área de conhecimento em que atuam." (BRASIL, 2014, p. 12).

O mesmo documento apresenta dados históricos e argumentos que corroboram para a compreensão da necessidade de formação em nível superior, como, quando, na página 48, destaca que "A formação acadêmica do professor é condição essencial para que assuma, efetivamente, as atividades docentes e curriculares em todas as etapas e modalidades, seja no ambiente escolar, seja nos sistemas de ensino." (BRASIL, 2014, p. 48).

É possível compreender também que, na elaboração das metas constantes do Plano Nacional de Educação, foi considerada a situação das pessoas formadas na modalidade normal, em nível médio. Para esse público, o documento aponta que

Aos docentes com formação de nível médio na modalidade normal, não licenciados ou licenciados em área diversa da atuação docente, em efetivo exercício, deverá ser garantida a formação específica em sua área de atuação, mediante a implementação de cursos e programas [...] (BRASIL, 2014, p. 49)

Depreende-se, ante o exposto, que, com base em recomendações internacionais e nacionais, a legislação brasileira aponta como ideal a formação dos professores para atuação na educação básica em nível superior. Na primeira versão da LDBEN, o parágrafo 4으 do Artigo 87 afirmava que até 2007 , somente seriam aceitos professores com formação nesse nível de ensino, com a seguinte redação: "Até o fim da Década da Educação somente serão admitidos professores habilitados em nível superior ou formados por treinamento em serviço" (BRASIL, 1996). Contudo, o referido parágrafo foi revogado em 2013, pela Lei 12.796, o que leva a à compreensão de que, apesar do ideal posto, ainda é aceita a habilitação na modalidade normal, ou seja, aquela obtida em nível médio, ofertada pelos cursos de formação de docentes, o antigo magistério.

Analisando também o ideal de formação proposto pelo Plano Nacional de Educação 2014/2024, percebe-se que, apesar do apontamento da necessidade de habilitação em nível superior, é considerada a presença daqueles com formação em nível médio, por duas razões: pela presença desses profissionais no mercado de trabalho, aprovados em concursos públicos de provas e títulos e, também, pela possibilidade de aqueles que têm tal formação e não são licenciados assumirem os cargos, com base na previsão legal.

Como ocorre com toda legislação, as previsões e determinações expostas precisam encontrar condições de concretude na realidade prática. No caso específico, a dissonância entre o ideal e o minimamente aceitável - aspectos presentes em uma mesma lei -, tem gerado ambiguidades 
de interpretações na aplicabilidade das recomendações legais. Como comumente ocorre, a educação infantil (primeira etapa do ensino fundamental) e os primeiros anos do ensino fundamental são de responsabilidade dos municípios, tendência encontrada também na região de Maringá. Sendo assim, a ambiguidade de interpretação - exigência de formação em nível médio e em nível superior - tem feito com que os profissionais encontrem situações diferentes em variados lugares. Alguns municípios exigem a formação do professor em licenciaturas; outros, admitem o ingresso no cargo por meio da modalidade normal.

\section{DISCUSSÃO}

Para uma melhor compreensão do que está sendo cobrado como habilitação mínima para ingresso na carreira do magistério da educação básica, foi selecionado o conjunto de municípios integrantes da região de Maringá, mais especificamente as cidades da Amusep (Associação dos Municípios do Setentrião Paranaense). Os dados sobre os municípios que integram a região foram coletados no endereço eletrônico oficial da associação (www.amusep.com.br). No total, 30 municípios compõem a organização citada, sendo a maior Maringá, com 403.063 moradores, e a menor Santa Inês, com 1.818 habitantes, de acordo com o Censo do IBGE (Instituto Brasileiro de Geografia e Estatística).

A análise sobre as exigências para tomar posse como professor levou em consideração os editais de concursos públicos publicados nos últimos dez anos, com base em diferentes plataformas virtuais, entre elas os portais de transparência das prefeituras correspondentes aos municípios. Isso porque, de acordo com o inciso I do Artigo 67 da LDBEN, "ingresso exclusivamente por concurso público de provas e títulos" é condição necessária para a valorização do profissional da educação (BRASIL, 1996). Em outras palavras, é preciso esclarecer que o acesso ao cargo de professor ocorre mediante concursos públicos, regidos pelos editais respectivos.

Com base nas buscas, foram encontrados 23 editais de concursos da última década para o cargo de professor de educação infantil ou educador infantil - profissional responsável pelo atendimento às crianças de 0 a 5 anos em creches e pré-escolas. Já em relação ao cargo de professor para os cinco primeiros anos do ensino fundamental, foram encontrados 26 editais. Para os cargos de atuação na educação infantil, apenas cinco municípios exigiram formação em nível superior no último certame, sendo eles Astorga, Flórida, Iguaraçu, São Jorge do Ivaí e Sarandi. Considerado esse dado, as análises que se sucederam tiveram por foco apenas o cargo de professor para os primeiros anos do ensino fundamental.

Os municípios que realizaram concursos públicos para provimento do cargo de professor do ensino fundamental nos últimos dez anos são: Ângulo (último certame em 2014); Astorga (2013); Atalaia (2009); Colorado (2012); Doutor Camargo (2016); Floraí (2014); Floresta (2013), Flórida (2014); Iguaraçu (2017); Itaguajé (2014); Itambé (2013); Ivatuba (2015); Lobato (2017); Mandaguaçu (2017); Mandaguari (2010); Marialva (2014); Maringá (2016); Munhoz de Melo (2014); Nova Esperança (2016); Paiçandu (2014); Paranacity (2011); Presidente Castelo Branco (2012); Santa Inês (2015); Santo Inácio (2015); Sarandi (2016) e Uniflor (2016). Dentre as 26 cidades, 15 indicaram, por meio dos editais, a aceitação da formação em nível médio, na modalidade normal, para posse no cargo, o que representa $57,69 \%$ do total. 10 municípios exigiram formação em nível superior, em cursos de licenciatura ou normal superior, o que representa $38,46 \%$ da totalidade analisada. Um município dentre os que sofreram a análise apontou aceitar a formação em nível médio se o candidato/profissional, ao tomar posse, tiver pelo menos 120 horas cursadas de uma licenciatura; portanto, esse município, que representa 3,85\% do total, situa-se no campo intermediário.

A tabela abaixo indica a sequência de municípios, por ordem alfabética, apontando as exigências de formação mínima nos últimos editais de concursos públicos para professor do ensino fundamental: 
Tabela 1. Municípios da Amusep e a exigência de formação mínima dos editais de concursos públicos para professor do ensino fundamental

\begin{tabular}{|c|c|}
\hline MUNICÍPIO & EXIGÊNCIA MÍNIMA DE FORMAÇÃO \\
\hline ÂNGULO & NÍVEL MÉDIO \\
\hline ASTORGA & PEDAGOGIA OU CNS \\
\hline ATALAIA & NÍVEL MÉDIO \\
\hline COLORADO & MÉDIO C LICENCIATURA OU PEDAGOGIA \\
\hline DOUTOR CAMARGO & LICENCIATURA \\
\hline FLORAí & NÍVEL MÉDIO \\
\hline FLORESTA & NÍVEL MÉDIO \\
\hline FLÓRIDA & PEDAGOGIA OU CNS \\
\hline IGUARAÇU & NÍVEL MÉDIO COM LICENCIATURA \\
\hline ITAGUAJÉ & NÍVEL MÉDIO \\
\hline ITAMBÉ & NÍVEL MÉDIO \\
\hline IVATUBA & PEDAGOGIA \\
\hline LOBATO & NÍVEL MÉDIO \\
\hline MANDAGUAÇU & NÍVEL MÉDIO \\
\hline MANDAGUARI & NÍVEL MÉDIO \\
\hline MARIALVA & NÍVEL MÉDIO \\
\hline MARINGÁ & PEDAGOGIA OU CNS \\
\hline MUNHOZ DE MELLO & NÍVEL MÉDIO \\
\hline NOSSA SENHORA DAS GRAÇAS & (EDITAL DO PERIOODO NÃO ENCONTRADO) \\
\hline NOVA ESPERANÇA & MÉDIO COM LICENCIATURA OU PEDAGOGIA \\
\hline OURIZONA & (EDITAL DO PERÍODO NÃO ENCONTRADO) \\
\hline PAIÇANDU & NÍVEL MÉDIO \\
\hline PARANACITY & NÍVEL MÉdIO \\
\hline PRESIDENTE CASTELO BRANCO & NÍVEL MÉdIO \\
\hline SANTA FÉ & (EDITAL DO PERÍODO NÃO ENCONTRADO) \\
\hline SANTA INÊS & NÍVEL MÉDIO, COM 120 HORAS EM PEDAGOGIA OU CNS \\
\hline SANTO INÁCIO & NÍVEL MÉDIO \\
\hline SÃO JORGE DO IVAÍ & (EDITAL DO PERIODO NÃO ENCONTRADO) \\
\hline SARANDI & NÍVEL MÉDIO COM LICENCIATURA \\
\hline UNIFLOR & NÍVEL MÉDIO COM LICENCIATURA \\
\hline \multirow[t]{5}{*}{ Cor } & Significado \\
\hline & Exigência de nível médio \\
\hline & Exigência de nível superior \\
\hline & Edital do período não encontrado \\
\hline & Exigência de nível médio com matrícula em nível superior \\
\hline
\end{tabular}

Fonte: Elaborado pelo Autor

Com base nessas informações, o gráfico abaixo apresenta o percentual de cada categoria apurada: 
Gráfico 1. Percentual de municípios que fazem parte de cada categoria de exigência de formação mínima para professor do ensino fundamental

\section{Formação Mínima Exigida}

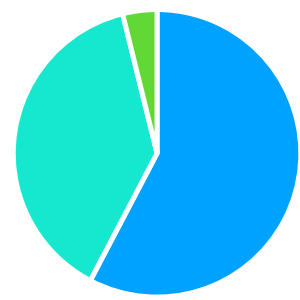

- Nível médio (modalidade normal) 57,69\%

- Nível superior 38,46\%

- Nível médio com matrícula no nível superior 3,85\%

Fonte: Elaborado pelo Autor

Várias são as maneiras pelas quais se pode avaliar o rendimento dos municípios analisados. Foi escolhida, nesse trabalho, a avaliação dos resultados das cidades em questão na última avaliação do Ideb. É importante destacar que não se pretende apontar os dados como únicos indicadores da qualidade do ensino e sua direta relação com as exigências do edital, porque lançar-se a essa tarefa seria valorizar apenas a superficialidade das informações. Por outro lado, acredita-se que as informações podem servir como um parâmetro e motivar pesquisadores a novas pesquisas.

Os dados de 2015, disponíveis no portal www.ideb.inep.gov.br, apontam que a média das notas entre os 15 municípios que exigem formação em nível médio, na modalidade normal, é de aproximadamente 6,1. Entre os dez municípios que exigem nível superior, a média é, também, de 6,1. O município que aceita a formação em nível médio com matrícula no nível superior obteve nota 5,8. Os dados encontram-se reunidos no gráfico abaixo:

Gráfico 2. Média dos Municípios no Ideb 2015

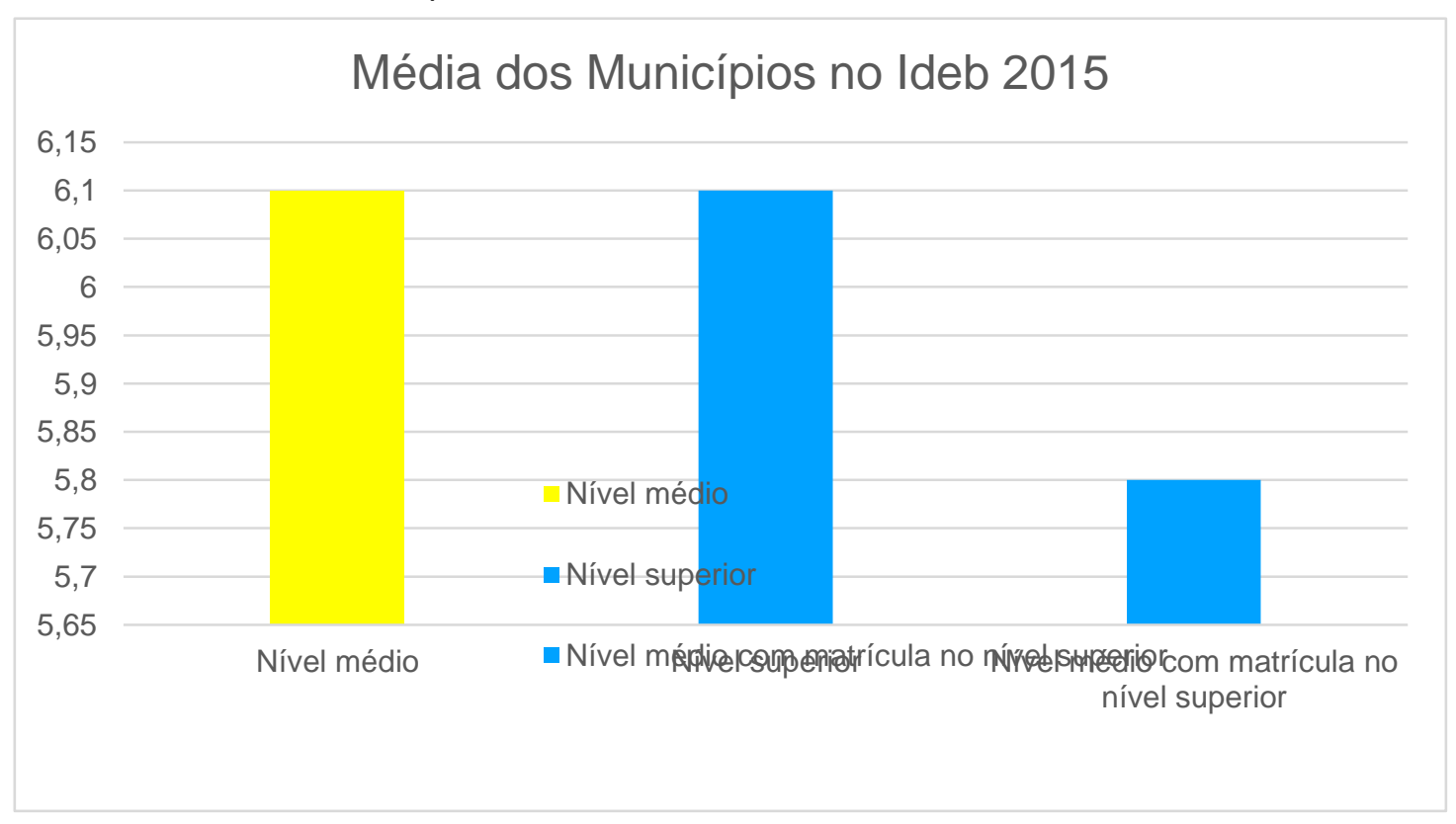

Fonte: Elaborado pelo autor. 
Comparando o município que obteve a maior nota no Ideb com o que teve a menor nota, entre as cidades analisadas, averígua-se que ambos exigem apenas formação em nível médio para assumir concurso como professor do ensino fundamental. Atalaia é o município com a maior nota, 8,1, enquanto Itaguajé apresenta o menor índice, 4,9. Os dados estão reunidos na tabela abaixo:

Tabela 2. Município com nota mais alta e município com nota mais baixa no Ideb 2015

\begin{tabular}{|l|l|}
\hline Nota & Município \\
\hline 8,1 & $\begin{array}{l}\text { Atalaia (Exige formação em nível } \\
\text { médio) }\end{array}$ \\
\hline 4,9 & $\begin{array}{l}\text { Itaguajé } \\
\text { (Exige formação em nível médio) }\end{array}$ \\
\hline
\end{tabular}

Fonte: Elaborado pelo autor.

\section{CONCLUSÃO}

É possível perceber que, para além do texto, há a defesa de privatização da educação e a diminuição do papel do Estado. É possível, também, compreender que isso não é dito de forma direta, talvez porque, se assim ocorrer, não encontre apoio popular e/ou político. É preciso levar em consideração que vários autores podem ter sua participação nesta matéria, mas, como ocorre nos órgãos governamentais, a aprovação para a publicação ocorre com base no segmento político e partidário defendido.

Apesar de não haver uma única forma de leitura dos textos e discursos, em Foucault e outros representantes da $A D$, encontra-se inquietude. É preciso sempre ir além do que as palavras estão a dizer superficialmente. O rápido exercício de análise da matéria em questão serve para esse pensar e para refletir, também, sobre as investidas neoliberais, principalmente na área da educação. 


\section{REFERÊNCIAS}

AMUSEP. Sítio eletrônico. Disponível em: http://amusep.com.br/site/. Acesso em: 31 Jul. 2018.

BRASIL. Constituição (1988). Constituição da República Federativa do Brasil. Brasília, DF, Senado, 1988.

BRASIL. Leis de Diretrizes e Bases da Educação Nacional. 1996. Disponível em: <http://www.planalto.gov.br/Ccivil_03/leis/L9394.htm> Acesso em: 31. Jul.2018.

BRASIL. Plano Nacional de Educação. 2014. Disónível em: http://www.observatoriodopne.org.br/uploads/reference/file/439/documento-referencia.pdf. Acesso em: 31. Jul. 2018.

INEP.Sítio eletrônico do Índice de Desenvolvimento da Educação Básica. Disponível em: http://ideb.inep.gov.br/. Acesso em: 31. Jul. 2018. 